\title{
Solid Free-Form Fabrication of Metallic Components
}

\author{
Akio Kagawa ${ }^{1, a}$, Masayuki Mizumoto ${ }^{1, b}$ and Takeshi Ohgai ${ }^{1, c}$ \\ ${ }^{1}$ Department of Materials Science and Engineering, Nagasaki University, 1-14 Bunkyo-machi, \\ Nagasaki 852-8521, JAPAN \\ aakagawa@net.nagasaki-u.ac.jp, ㄹmizumoto@net.nagasaki-u.ac.jp, cohgai@net.nagasaki-u.ac.jp
}

Keywords: Fused deposition method, Aluminum alloy, Shape stability, Surface smoothness, Tensile strength

\begin{abstract}
The influence of process parameters on shape stability and surface smoothness of cylindrical and rectangular castings produced by fused spinning deposition (FSD) method was investigated. The optimum conditions to control the shape and smoothness of side surface of the castings produced by the FSD method without water-cooling were limited to a narrow range of process parameters. The casting with a stable shape and a smooth side surface was obtained with the aid of water-cooling. The tensile strength of the castings produced by the FSD method was 1.4 times higher than those of the specimens cast into metal-mold and sand-mold, due to a finer equiaxed grain structure of the FSD castings. Employing the combination of the deposition patterns for tube and solid castings, some practical metallic components were fabricated by the FSD method.
\end{abstract}

\section{Introduction}

Conventional metal castings process requires the preparation and the shakeout of the mold since they are fabricated by casting a melt into the metal or sand mold. Recently, an effort has been directed toward a reduction in cost and time for casting processes. Fused spinning deposition (FSD) method is a process that castings are shaped without a mold by depositing a molten metal and solidified on a substrate. The FSD method is expected to result in the simplification of casting process due to its mold-free process. In addition, an improvement in mechanical properties of the castings fabricated by the FSD method is expected since there are few porosities and fine equiaxed grains in the castings. In the previous works, optimum conditions to control the shape of hollow tube castings fabricated by the FSD method have been examined [1, 2]. Since practical components have a complex shape, which is a combination of hollow tube parts and solid parts. In the present work, optimum conditions of shape control and surface smoothness of solid parts, that is, cylindrical and rectangular castings, were investigated by changing casting sizes and driving velocity of the substrate. Tensile strength of the FSD castings was measured and compared with those of the specimens cast into the metal-mold and sand-mold. In addition, the castings having a fundamental shape of practical metallic components were fabricated as application of the FSD method.

\section{Experimental Procedure}

$\mathrm{Al}-4 \mathrm{mass} \% \mathrm{Cu}$ alloy bars were prepared by melting pure materials and casting the melt into a metal-mold of $12 \mathrm{~mm}$ inner diameter. The cylindrical bar was set in a quartz tube with a small nozzle of $0.4 \mathrm{~mm}$ diameter at the bottom. The experimental set up of the fused spinning deposition (FSD) apparatus is shown schematically in Fig. 1. After replacing the air in the quartz tube with Ar gas, the temperature of electric furnace was raised to $993 \mathrm{~K}$ and held for $20 \mathrm{~min}$. Then the melt was cooled to 943K (superheat of 20K) and held for $20 \mathrm{~min}$. After holding, the pressure of 0.12-0.13 MPa was applied on the melt surface in order to flow out the melt through the nozzle onto the copper substrate. Cylindrical castings were produced by driving the substrate, which rotates at $120 \mathrm{rpm}$, in X-axis direction horizontally and downward simultaneously. Rectangular castings were produced by driving the substrate in X-Y horizontal direction and downward simultaneously. Shape stability, surface smoothness and microstructure of the castings were investigated by changing casting sizes and 
driving velocity of the substrate. The microstructure was observed on the vertical sections of the castings with an optical microscope.
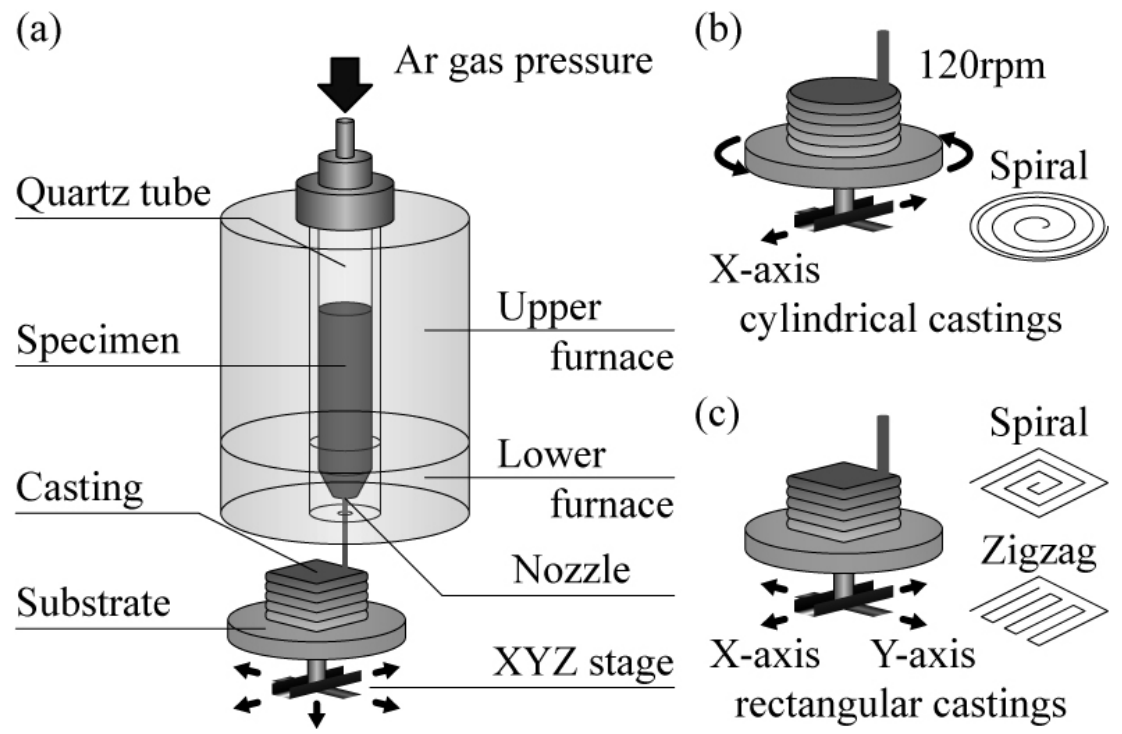

Fig. 1 Schematic drawing of (a) Fused spinning deposition (FSD) apparatus, and substrate driving pattern for (b) cylindrical and (c) rectangular castings.

\section{Results and Discussion}

Cylindrical castings. In order to attain the uniform thickness of a piled-up layer, the driving velocity in X-axis direction was accelerated from the outside to the center of the substrate. The appearances of cylindrical castings with different casting sizes for different driving accelerations of the substrate are shown in Fig. 2. The larger the casting size became, the rougher the side surface of the castings became. It is considered that an increase in casting size, that is, an increase in time interval of the melt deposition, resulted in a reduction in surface temperature of the lower layer and that heat from the upper melt was insufficient for remelting the surface of the lower layer. When casting size became smaller, the shape of the castings was collapsed because a decrease in casting size, that is, a decrease in time interval, caused a rise in the temperature of the casting. As for the effects of driving acceleration of the substrate, it is found that the optimum size of the castings required for shape stability and surface smoothness was about $30 \mathrm{~mm}$ for the driving acceleration of $12 \mathrm{~mm} / \mathrm{s}^{2}$. The larger the driving acceleration became, the rougher the side surface of the castings became. When the driving acceleration became smaller, the shape of the castings was collapsed. It is considered that a decrease in spiral track spacing due to the increase in driving acceleration causes the accumulation of heat in the casting and the shape of the casting cannot be maintained by surface tension. In the case of the casting size of $30 \mathrm{~mm}$, the optimum driving acceleration required for shape stability and surface smoothness was $12 \mathrm{~mm} / \mathrm{s}^{2}$. To obtain the castings with stable shape and smooth surface for different casting sizes, water-cooling was employed during the FSD process. Appearance and vertical section of the casting fabricated with water-cooling are also shown in Fig. 2. By employing water-cooling, the castings with stable shape and smooth surface were obtained even in the case where the shape of the castings were collapsed without water-cooling. To investigate the cooling effect on the microstructure of the castings, eutectic spacing was measured. The eutectic spacing measured on the vertical section of the air-cooled and water-cooled castings was shown in Fig. 3. In the case of air-cooling, the eutectic spacing increased with increasing the number of layers due to a decrease in cooling-rate of the casting, while, in the case of water-cooling, the eutectic spacing was almost 
constant and independent of the location. Thus, it is found that a constant cooling rate of the castings can be maintained by the aid of water-cooling.

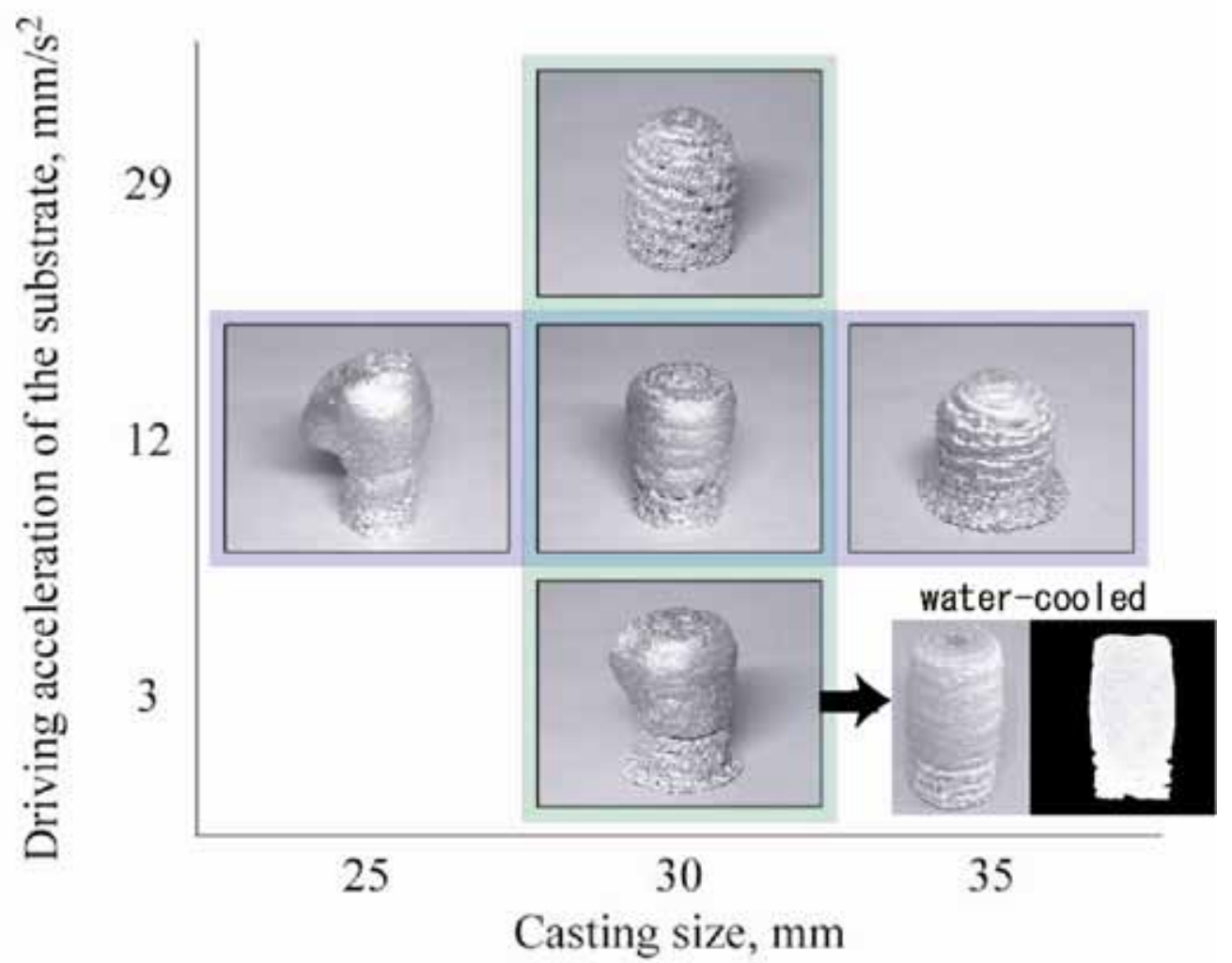

Fig. 2 Appearances of cylindrical castings with different casting diameter, fabricated at different accelerations of the substrate. ( ) : Vmax, $\mathrm{mm} / \mathrm{s}$

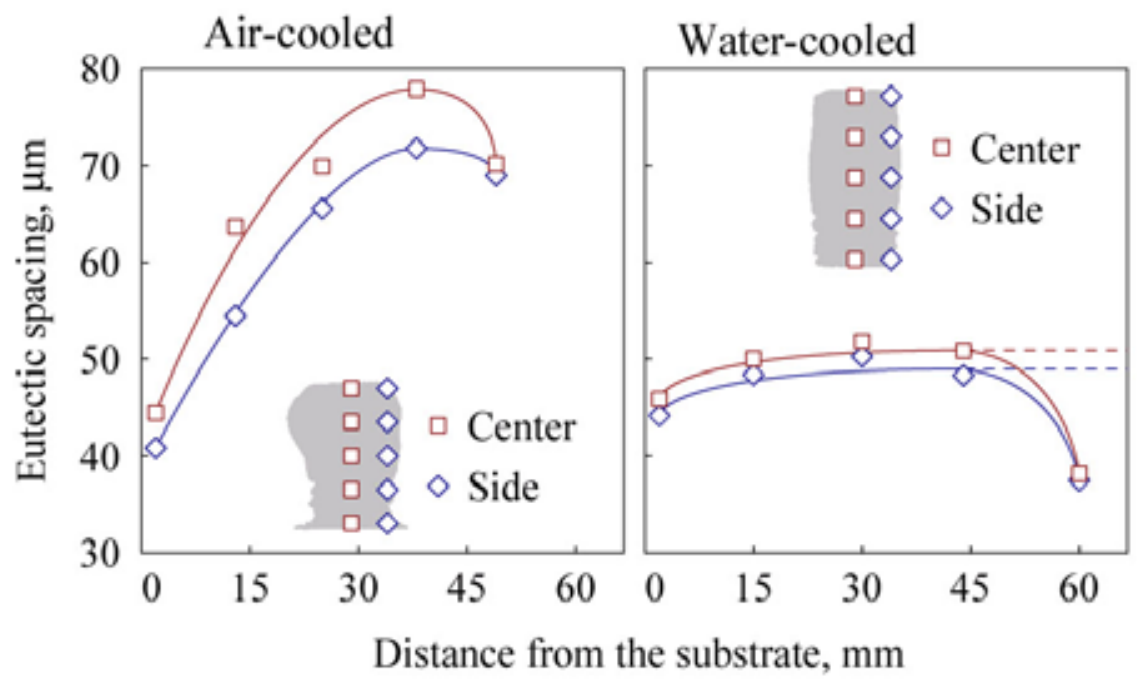

Fig. 3 Eutectic spacing of air cooled and water cooled castings. (acceleration : $a=3 \mathrm{~mm} / \mathrm{s}^{2}$, casting diameter : $D=30 \mathrm{~mm}$ ) 
Rectangular castings. The melt shape on the substrate was measured in order to select a suitable track spacing of the melt. The width, $W$, and one layer thickness, $t$, of the melt piled up on the substrate are measured as a function of the driving velocity of the substrate, $V$. The thickness decreased with increasing the driving velocity of the substrate, while the width of the melt was kept almost constant around $5 \mathrm{~mm}$. Thus the track spacing of the melt was set to be $4 \mathrm{~mm}$ in this work. In filling the inside of the square shaped layer, a combination of spiral and zigzag patterns was applied so that the time interval of melt deposition became almost constant at any position in the casting. It was found that the optimum conditions to obtain a stable rectangular shape and a smooth side surface of the castings were limited to the casting size of $25 \mathrm{~mm}$ for the driving velocity of $25 \mathrm{~mm} / \mathrm{s}$. Similar to the cylindrical castings, the water-cooling was effective to obtain castings with a stable shape and a smooth surface.

Tensile strength of castings fabricated by FSD method. Tensile strength of the castings fabricated by the FSD method was measured in order to compare with metal-mold and sand-mold castings. Tensile strength of the FSD castings are plotted in Fig. 4 in comparison with those of metal-mold and sand-mold castings. Tensile strength of the specimens fabricated by the FSD method was 1.4 times higher than those of the metal-mold and sand-mold cast specimens. The macro and microstructures of the FSD casting, the metal-mold and sand-mold castings are shown in Fig. 5. The FSD castings have

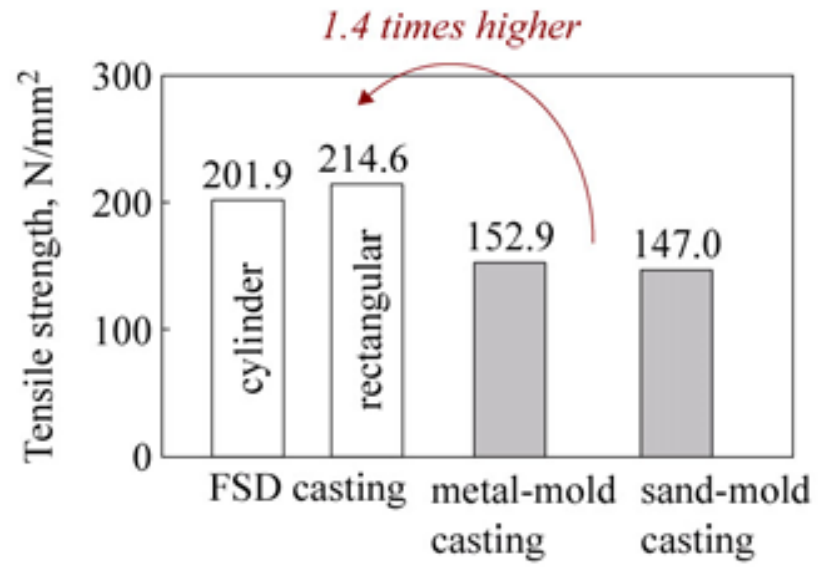

Fig. 4 (a) Specimen size for tensile test and (b) tensile strength of FSD, metal-mold and sand-mold castings.

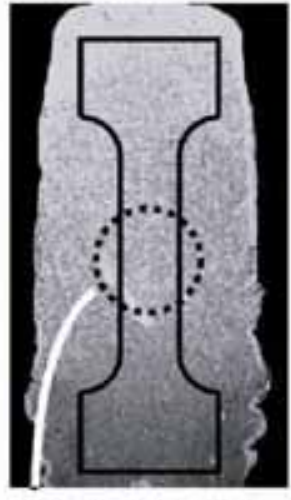

a) FSD casting

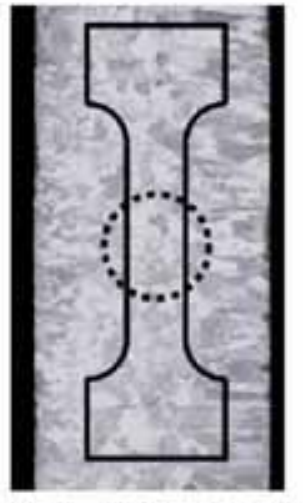

b) metal-mold casting

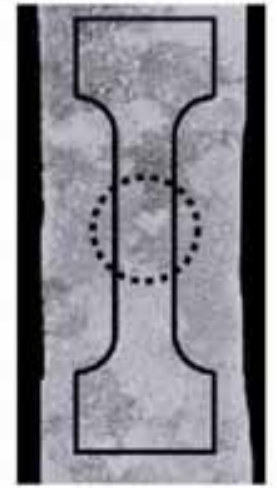

c) sand casting
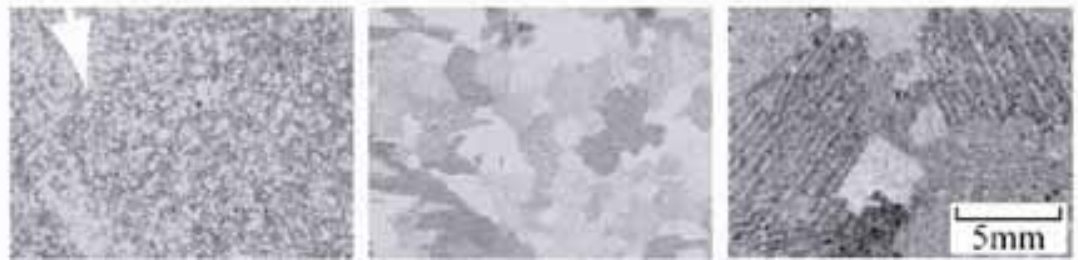

Fig. 5 Macro and microstructures of (a) FSD, (b) metal-mold and (c) sand-mold castings 
a fine equiaxed grain structure due to a repetition of melting and solidification during the casting process. The fine equiaxed grain structure may be formed by the following mechanism. When a solid/liquid coexisting region is generated by remelting the surface of lower layer due to a heat from the upper melt, a part of dendrite in the solid/liquid coexisting region were fragmented and solidified again, resulting in a fine equiaxed grain structure. On the other hand, in the metal-mold casting, a columnar structure was observed in the side locations and a coarse equiaxed grain structure was observed in the center of the castings. The sand-mold castings had a coarser equiaxed grain structure due to its small cooling rate. It is considered that these differences in the microstructure of the castings resulted in the difference in tensile strength. The results indicate that the castings produced by the FSD method exhibit a superior tensile strength due to a fine equiaxed grain structure.

Application. The optimum conditions for basic shapes, such as cylindrical and rectangular shape tube castings and solid castings were applied to the fabrication of practical metallic components. Fig. 6(a) shows the appearance of a reverse pyramid shape casting, fabricated with the inclined deposition of 45 degrees outwards and the melt track spacing of $1.3 \mathrm{~mm}$. It is found that the inclination angle of the side surface of the FSD castings was able to be controlled by changing the track spacing. Fig. 6(b) and c show the appearances and the vertical sections of two types castings with inside through-holes, $\cap$-type and U-type, fabricated using a combination of the substrate driving patterns for rectangular shape hollow tube and solid castings. The castings with a complex shape of through-holes like turbine-blade can be fabricated using a combination of deposition patterns for these two type's through-holes castings. Fig. 6(d) shows the appearance of a wineglass shape casting which was obtained using the deposition patterns of the cylindrical tube and solid castings. The appearance of the FSD casting with a piston shape is shown in Fig. 6(e), which have a satisfactory shape in comparison with a practical one shown in Fig. 6(f).

(a)

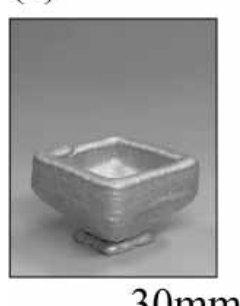

$30 \mathrm{~mm}$

(d)

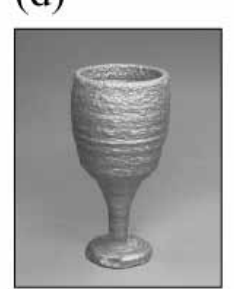

$30 \mathrm{~mm}$

(b)

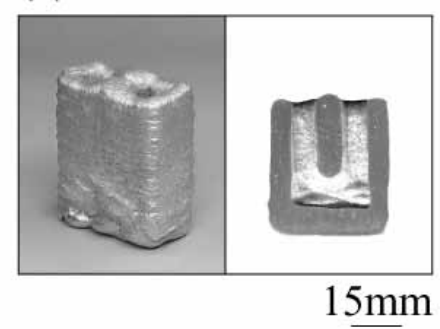

(e)

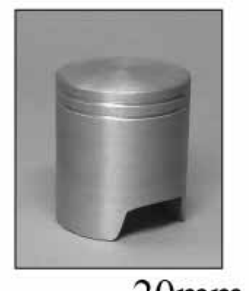

(c)

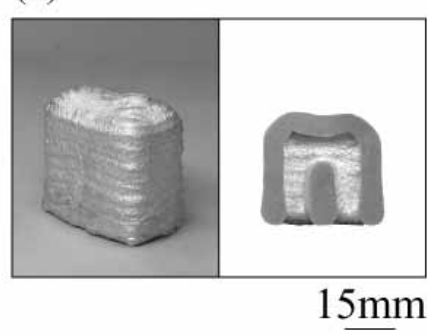

(f)

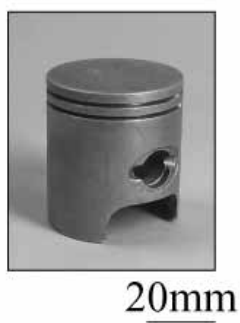

Fig. 6 Appearance of (a) reverse pyramid casting, (b) and (c) two type’s castings with different through-holes, (d) wineglass shape casting, (e) piston shape casting fabricated by FSD method and (f) practical piston.

\section{Conclusions}

The influence of process parameters on shape stability and surface smoothness of cylindrical and rectangular castings produced by FSD method was investigated by changing casting sizes and driving 
velocity of the substrate. Tensile strength of the castings produced by the FSD method was measured and compared with those of the specimens cast into metal-mold and sand-mold. As applications, some metallic components were fabricated by the FSD method. The results obtained are summarized as follows.

1. The optimum conditions to control the shape and smoothness of side surface of the castings produced by the FSD method without water-cooling were limited to a narrow range of process parameters.

2. The casting with a stable shape and a smooth side surface was obtained with the aid of water-cooling.

3. Tensile strength of the castings produced by the FSD method was 1.4 times higher than those of metal-mold and sand-mold cast specimens, due to a finer equiaxed grain structure of the FSD castings.

4. Employing a combination of deposition patterns for tube and solid castings, some practical metallic components were fabricated by the FSD method.

\section{References}

[1] A. Kagawa and T. Ishida, J. JFS 70(1998) 484

[2] K. Ohishi, T. Morimoto, M. Mizumoto and A. Kagawa, J. JFS 76(2004) 582 